\title{
Chaotic based Pteropus algorithm for solving optimal reactive power problem
}

\author{
Lenin Kanagasabai \\ Department of EEE, Prasad V. Potluri Siddhartha Institute of Technology, India
}

\begin{tabular}{l} 
Article Info \\
\hline Article history: \\
Received Jan 8, 2020 \\
Revised May 31, 2020 \\
Accepted Jun 9, 2020 \\
\hline
\end{tabular}

\section{Keywords:}

Chaotic Pteropus behaviour Optimal reactive power Transmission loss

\begin{abstract}
In this work, a Chaotic based Pteropus algorithm (CPA) has been proposed for solving optimal reactive power problem. Pteropus algorithm imitates deeds of the Pteropus. Normally Pteropus while flying it avoid obstacles by using sonar echoes, particularly utilize time delay. To the original Pteropus algorithm chaotic disturbance has been applied and the optimal capability of the algorithm has been improved in search of global solution. In order to augment the population diversity and prevent early convergence, adaptively chaotic disturbance is added at the time of stagnation. Furthermore, exploration and exploitation capability of the proposed algorithm has been improved. Proposed CPA technique has been tested in standard IEEE 14,300 bus systems \& real power loss has been considerably reduced.
\end{abstract}

This is an open access article under the CC BY-SA license.

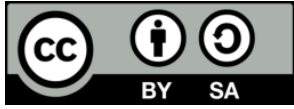

\section{Corresponding Author:}

Lenin Kanagasabai,

Department of EEE,

Prasad V. Potluri Siddhartha Institute of Technology,

Kanuru, Vijayawada, Andhra Pradesh, 520007, India.

Email: gklenin@gmail.com

\section{INTRODUCTION}

To have secure \& economic, operations of the power system optimal reactive power problem plays a prime role. Numerous conventional methods [1-6] have been successfully solved the problem. But difficulty found in handling the inequality constraints. Various types of evolutionary algorithms [7-18] applied to solve the problem. This paper projects chaotic Pteropus algorithm (CPA) for solving reactive power problem. Pteropus algorithm is designed based on the actions of Pteropus. while flying it avoid obstacles by using sonar echoes, particularly utilize time delay; happened while release and reflection of echo which has been utilized during the period of for course-plotting. In Projected algorithm echolocation feature is utilized in the algorithm and chaos theory intermingled in the flowing process. In order to augment the population diversity and prevent early convergence, adaptively chaotic disturbance $P_{c}$ is added at the time of stagnation. Projected CPA algorithm has been tested in standard IEEE 14,300 bus systems \& simulation study show the best performance of the projected algorithm in reducing the real power loss.

\section{PROBLEM FORMULATION}

The key objective of the reactive power problem is to minimize the system real power loss \& given as,

$$
P_{\text {loss }}=\sum_{k=(i, j)}^{n} g_{k}\left(V_{i}^{2}+V_{j}^{2}-2 V_{i} V_{j} \cos \theta_{i j}\right)
$$


Voltage deviation magnitudes (VD) is stated as follows,

Minimize $\mathrm{VD}=\sum_{\mathrm{k}=1}^{\mathrm{nl}}\left|\mathrm{V}_{\mathrm{k}}-1.0\right|$

Load flow equality constraints:

$$
\begin{aligned}
& P_{G i}-P_{D i}-V_{i \sum_{j=1}^{n b} V_{j}}\left[\begin{array}{cc}
G_{i j} & \cos \theta_{i j} \\
+B_{i j} & \sin \theta_{i j}
\end{array}\right]=0, i=1,2 \ldots, n b \\
& Q_{G i}-Q_{D i}-V_{i \sum_{j=1}^{n b} V_{j}}\left[\begin{array}{cc}
G_{i j} & \sin \theta_{i j} \\
+B_{i j} & \cos \theta_{i j}
\end{array}\right]=0, i=1,2 \ldots, n b
\end{aligned}
$$

Inequality constraints are:

$$
\begin{aligned}
& V_{\mathrm{Gi}}^{\min } \leq \mathrm{V}_{\mathrm{Gi}} \leq \mathrm{V}_{\mathrm{Gi}}^{\max }, \mathrm{i} \in \mathrm{ng} \\
& \mathrm{V}_{\mathrm{Li}}^{\min } \leq \mathrm{V}_{\mathrm{Li}} \leq \mathrm{V}_{\mathrm{Li}}^{\max }, \mathrm{i} \in \mathrm{nl} \\
& \mathrm{Q}_{\mathrm{Ci}}^{\min } \leq \mathrm{Q}_{\mathrm{Ci}} \leq \mathrm{Q}_{\mathrm{Ci}}^{\max }, \mathrm{i} \in \mathrm{nc} \\
& \mathrm{Q}_{\mathrm{Gi}}^{\min } \leq \mathrm{Q}_{\mathrm{Gi}} \leq \mathrm{Q}_{\mathrm{Gi}}^{\max }, \mathrm{i} \in \mathrm{ng} \\
& \mathrm{T}_{\mathrm{i}}^{\min } \leq \mathrm{T}_{\mathrm{i}} \leq \mathrm{T}_{\mathrm{i}}^{\max }, \mathrm{i} \in \mathrm{nt} \\
& \mathrm{S}_{\mathrm{Li}}^{\min } \leq \mathrm{S}_{\mathrm{Li}}^{\max }, \mathrm{i} \in \mathrm{nl}
\end{aligned}
$$

\section{PTEROPUS ALGORITHM}

Pteropus algorithm imitates deeds of the Pteropus. Normally Pteropus while flying it avoid obstacles by using sonar echoes, particularly utilize time delay; happened while release and reflection of echo which has been utilized during the period of for course-plotting. Generalized rules for Pteropus algorithm are:

a. To sense the distance- all Pteropus use echolocation

b. In arbitrarily mode Pteropus fly with velocity $\vartheta_{i}$ at position $y_{i}$ with a fixed frequencyf $f_{\min }$, varying wavelength $\lambda$ and loudness $A_{0}$ to search for prey. They can robotically adjust the frequency of their released pulses and regulate the rate of pulse emission $r \in[0 ; 1]$, with reference to the propinquity of the goal.

c. Loudness will vary from a large (positive) $A_{0}$ to a minimum constant value $A_{\text {min }}$.

Pteropus algorithm

Initialize the population

Pulse frequency defined in the range of $G_{i} \in\left[Q_{\min }, G_{\max }\right]$

$\mathrm{r}_{\mathrm{i}}, \mathrm{A}_{\mathrm{i}}$ are defined

While ( $\mathrm{t}<\mathrm{T}_{\text {maximum }}$ )

By adjustment of frequency new solutions are generated

Obtained Solution \& velocity are updated

If $\left(\right.$ random $\left.(0 ; 1)>r_{i}\right)$

Form the solution best one is selected

Around the best solution - a local solution will be engendered

End if

In arbitrary mode new solutions are generated

If (random $(0 ; 1)<\mathrm{A}_{\mathrm{i}}$ and $\mathrm{f}\left(\mathrm{y}_{\mathrm{i}}\right)<\mathrm{f}(\mathrm{y})$ )

New solutions are formed

$r_{i}$ and $A_{i}$ values are increased

End if

Current best is found by ranking the Pteropus in order

End while

Output the optimized results

Virtual Pteropus are moved to form new solutions by the following,

Int J Adv Appl Sci, Vol. 9, No. 4, December 2020: 265 - 269 


$$
\begin{aligned}
& \mathrm{G}_{\mathrm{i}}^{(\mathrm{t})}=\mathrm{G}_{\min }+\left(\mathrm{G}_{\max }-\mathrm{G}_{\min }\right) \cup(0,1), \\
& \mathrm{l}_{\mathrm{i}}^{(\mathrm{t}+1)}=\mathrm{l}_{\mathrm{i}}^{\mathrm{t}}+\left(\mathrm{y}_{\mathrm{i}}^{\mathrm{t}}-\text { best }\right) \mathrm{G}_{\mathrm{i}}^{(\mathrm{t})}, \\
& \mathrm{y}_{\mathrm{i}}^{(\mathrm{t}+1)}=\mathrm{y}_{\mathrm{i}}^{(\mathrm{t})}+\mathrm{l}_{\mathrm{i}}^{(\mathrm{t})}
\end{aligned}
$$

Existing finest solution has been modified by the following,

$$
y^{(t)}=\text { best }+\epsilon A_{i}^{(t)}(2 U(0,1)-1),
$$

When ri increases, Ai will decrease; when a Pteropus finds a prey \& it mathematically written as follows,

$$
A_{i}^{(t+1)}=\alpha A_{i}^{(t)}, r_{i}^{(t)}=r_{i}^{(0)}[1-\exp (-\gamma \epsilon)]
$$

To improve the Pteropus algorithm chaotic disturbance [19-21] is introduced. Here, variance $\sigma^{2}$ demonstrates the converge degree of all particles.

$$
\begin{aligned}
& \sigma^{2}=\sum_{i=1}^{N}\left[\left(f_{i}-f_{\text {avg }}\right) / f\right]^{2} \\
& f=\max \left\{1, \max \left\{\left|f_{i}-f_{\text {avg }}\right|\right\}\right\} \\
& y_{i d}(t+1)=\mu y_{i d}(t)\left(1-y_{i d}(t)\right)
\end{aligned}
$$

In order to augment the population diversity and prevent early convergence, adaptively chaotic disturbance $P_{c}$ is added at the time of stagnation. Thus, $P_{c}$ is modified as $P_{c}^{\prime}$.

$$
\begin{aligned}
& E_{c d}^{\prime}(t+1)=p_{c d}(t)+Z_{i d}\left(2_{y i d}(t)-1\right) \\
& Z_{i d}=\beta\left|p_{c d}(t)-E_{i d}(t)\right|
\end{aligned}
$$

\section{Chaotic based Pteropus Algorithm}

Initialize the population

Pulse frequency defined in the range of $G_{i} \in\left[G_{\min }, G_{\max }\right]$

$\mathrm{r}_{\mathrm{i}}, \mathrm{A}_{\mathrm{i}}$ are defined

While ( $\left.\mathrm{t}<\mathrm{T}_{\text {maximum }}\right)$

By adjustment of frequency new solutions are generated

Obtained Solution \& velocity are updated

Using the equations update the velocities and locations

$\mathrm{G}_{\mathrm{i}}^{(\mathrm{t})}=\mathrm{G}_{\text {min }}+\left(\mathrm{G}_{\max }-\mathrm{G}_{\text {min }}\right) \cup(0,1)$,

$\mathrm{l}_{\mathrm{i}}^{(\mathrm{t}+1)}=\mathrm{l}_{\mathrm{i}}^{\mathrm{t}}+\left(\mathrm{y}_{\mathrm{i}}^{\mathrm{t}}-\right.$ best $) \mathrm{G}_{\mathrm{i}}^{(\mathrm{t})}$,

$\mathrm{y}_{\mathrm{i}}^{(\mathrm{t}+1)}=\mathrm{y}_{\mathrm{i}}^{(\mathrm{t})}+\mathrm{l}_{\mathrm{i}}^{(\mathrm{t})}$

If $\left(\operatorname{random}(0 ; 1)>r_{i}\right)$

Form the solution best one is selected

Around the best solution - a local solution will be engendered

End if

In arbitrary mode new solutions are generated

If (random $(0 ; 1)<\mathrm{A}_{\mathrm{i}}$ and $\mathrm{f}\left(\mathrm{y}_{\mathrm{i}}\right)<\mathrm{f}(\mathrm{y})$ )

New solutions are formed

$\mathrm{r}_{\mathrm{i}}$ and $\mathrm{A}_{\mathrm{i}}$ values are increased

End if

Current best is found by ranking the Pteropus in order

End while

Output the optimized results 


\section{SIMULATION RESULTS}

Proposed Chaotic based Pteropus algorithm (CPA) has been tested in standard IEEE 14,300 bus systems and comparison has been done with standard algorithms. Simulation output clearly indicates about the efficiency of the proposed algorithm in reducing the real power loss.

At first in standard IEEE 14 bus system the validity of the proposed CPA algorithm has been tested \& comparison results are presented in Table 1 .

Table 1. Comparison results

\begin{tabular}{llll}
\hline Control variables & ABCO [22] & IABCO [22] & Projected CPA \\
\hline V1 & 1.06 & 1.05 & 1.03 \\
V2 & 1.03 & 1.05 & 1.00 \\
V3 & 0.98 & 1.03 & 1.01 \\
V6 & 1.05 & 1.05 & 1.00 \\
V8 & 1.00 & 1.04 & 0.99 \\
Q9 & 0.139 & 0.132 & 0.129 \\
T56 & 0.979 & 0.960 & 0.969 \\
T47 & 0.950 & 0.950 & 0.948 \\
T49 & 1.014 & 1.007 & 1.002 \\
Ploss (MW) & 5.92892 & 5.50031 & 5.49842 \\
\hline
\end{tabular}

Then IEEE 300 bus system [23] is used as test system to validate the performance of the proposed CPA algorithm. Table 2 shows the comparison of real power loss obtained after optimization. Real power loss has been considerably reduced when compared to the other standard reported algorithms.

Table 2 comparison of real power loss

\begin{tabular}{lllll}
\hline Parameter & Method EGA [24] & Method EEA [24] & Method CSA [25] & Projected CPA \\
\hline PLOSS (MW) & 646.2998 & 650.6027 & 635.8942 & 627.1564 \\
\hline
\end{tabular}

\section{CONCLUSION}

In this paper, chaotic based Pteropus algorithm (CPA) has been successfully solved the optimal reactive power problem. Natural actions of Pteropus has been effectively imitated and modelled to solve the problem. An adaptive chaotic disturbance $P_{c}$ is added at the time of stagnation Performance of the Pteropus algorithm has been improved and better-quality solutions have been obtained. In addition, exploration and exploitation capability of the proposed algorithm has been enhanced. Proposed CPA technique has been tested in standard IEEE 14,300 bus systems \& real power loss has been considerably reduced.

\section{REFERENCES}

[1] K. Y. Lee, et al, "Fuel-cost minimisation for both real and reactive-power dispatches," Proceedings Generation, Transmission and Distribution Conference, vol. 131, no. 3, pp. 85-93, 1984.

[2] N. I. Deeb, et al., "An efficient technique for reactive power dispatch using a revised linear programming approach," Electric Power System Research, vol. 15, no. 2, pp. 121-134, 1988.

[3] M. R. Bjelogrlic, M. S. Calovic, B. S. Babic, et. al., "Application of Newton's optimal power flow in voltage/reactive power control," IEEE Trans Power System, vol. 5, no. 4, pp. 1447-1454, 1990.

[4] S. Granville, "Optimal reactive dispatch through interior point methods," IEEE Transactions on Power System, vol/issue: 9(1), pp. 136-146, 1994.

[5] N. Grudinin, "Reactive power optimization using successive quadratic programming method," IEEE Transactions on Power System, vol. 13, no. 4, pp. 1219-1225, 1998.

[6] Wei Yan, J. Yu, D. C. Yu and K. Bhattarai, "A new optimal reactive power flow model in rectangular form and its solution by predictor corrector primal dual interior point method," IEEE Trans. Pwr. Syst.,vol. 21,no. 1, pp. 61-67, 2006.

[7] Aparajita Mukherjee, Vivekananda Mukherjee, "Solution of optimal reactive power dispatch by chaotic krill herd algorithm," IET Gener. Transm. Distrib, vol. 9, no. 15, pp. 2351-2362, 2015.

[8] Hu, Z., Wang, X. \& Taylor, G. "Stochastic optimal reactive power dispatch: Formulation and solution method," Electr. Power Energy Syst., vol. 32, no. 6, pp. 615-621, 2010.

[9] Mahaletchumi A/P Morgan , Nor Rul Hasma Abdullah, Mohd Herwan Sulaiman, Mahfuzah Mustafa and Rosdiyana Samad, "Computational intelligence technique for static VAR compensator (SVC) installation 
considering multi-contingencies (N-m)," ARPN Journal of Engineering and Applied Sciences, vol. 10, no. 22, Dec 2015.

[10] Mohd Herwan Sulaiman, Zuriani Mustaffa, Hamdan Daniyal, Mohd Rusllim Mohamed and Omar Aliman, "Solving optimal reactive power planning problem utilizing nature inspired computing techniques," ARPN Journal of Engineering and Applied Sciences, vol. 10, no. 21, pp.9779-9785, Nov 2015.

[11] Mohd Herwan Sulaiman, Wong Lo Ing, Zuriani Mustaffa and Mohd Rusllim Mohamed, "Grey wolf optimizer for solving economic dispatch problem with valve-loading effects," ARPN Journal of Engineering and Applied Sciences, vol. 10, no. 21, pp. 9796-9801, Nov 2015.

[12] Pandiarajan, K. \& Babulal, C. K., "Fuzzy harmony search algorithm based optimal power flow for power system security enhancement," International Journal Electric Power Energy Syst., vol. 78, pp. 72-79. 2016.

[13] Mustaffa, Z., Sulaiman, M.H., Yusof, Y., Kamarulzaman, S.F., "A novel hybrid metaheuristic algorithm for short term load forecasting," International Journal of Simulation: Systems, Science and Technology, vol. 17, no. 41, pp. 6.1-6.6, 2017.

[14] Sulaiman, M.H., Mustaffa, Z., Mohamed, M.R., Aliman, O., "An application of multi-verse optimizer for optimal reactive power dispatch problems," International Journal of Simulation: Systems, Science and Technology, vol. 17, no. 41, pp. 5.1-5.5, 2017.

[15] Mahaletchumi A/P Morgan, Nor Rul Hasma Abdullah, Mohd Herwan Sulaiman,Mahfuzah Mustafa and Rosdiyana Samad, "Multi-objective evolutionary programming (MOEP) using mutation based on adaptive mutation operator (AMO) applied for optimal reactive power dispatch," ARPN Journal of Engineering and Applied Sciences, vol. 11, no. 14, Jul 2016.

[16] Rebecca Ng Shin Mei, Mohd Herwan Sulaiman, Zuriani Mustaffa, "Ant lion optimizer for optimal reactive power dispatch solution,” Journal of Electrical Systems, Special Issue AMPE2015, pp. 68-74, 2016.

[17] Mahaletchumi Morgan, Nor Rul Hasma Abdullah, Mohd Herwan Sulaiman, Mahfuzah Mustafa, Rosdiyana Samad, "Benchmark studies on optimal reactive power dispatch (ORPD) based multi-objective evolutionary programming (MOEP) using mutation based on adaptive mutation adapter (AMO) and polynomial mutation operator (PMO)," Journal of Electrical Systems, vol. 12, no.1, pp. 121-132, 2016.

[18] Rebecca Ng Shin Mei, Mohd Herwan Sulaiman, Zuriani Mustaffa, Hamdan Daniyal, "Optimal reactive power dispatch solution by loss minimization using moth-flame optimization technique," Applied Soft Computing, vol. 59, Pages 210-222, Oct 2017.

[19] X.S. Yang., "Bat algorithm for multi-objective optimisation," International Journal of Bio-Inspired Computation, vol. 3, no. 5, pp. 267-274, 2011.

[20] A. H. Gandomi, G. J. Yun, X.-S. Yang, and S. Talatahari, "Chaos-enhanced accelerated particle swarm optimization," Communications in Nonlinear Science and Numerical Simulation, vol. 18, no. 2, pp. 327-340, 2012.

[21] O. Abdel-Raouf, I. El-henawy and M. Abdel-Baset, "Chaotic harmony search algorithm with different chaotic maps for solving assignment problems," International Journal of Computational Engineering \& Management, vol. 17, pp. 10-15,2014.

[22] Chandragupta Mauryan Kuppamuthu Sivalingam1, Subramanian Ramachandran, Purrnimaa Shiva Sakthi Rajamani, "Reactive power optimization in a power system network through metaheuristic algorithms," Turkish Journal of Electrical Engineering \& Computer Science, vol. 25, no. 6, pp. 4615-4623, 2017.

[23] Power Systems Test Case Archive, [Online] Available:, http://www2.ee.washington.edu/research/pstca/

[24] S.S. Reddy, et al., "Faster evolutionary algorithm based optimal power flow using incremental variables," Electrical Power and Energy Systems, vol. 54, pp. 198-210, 2014.

[25] S. Surender Reddy, "Optimal reactive power scheduling using cuckoo search algorithm," International Journal of Electrical and Computer Engineering, vol. 7, no. 5, pp. 2349-2356, 2017. 